\title{
MITO Y ESTRATEGIAS PARA UN DESTINO ROMÁNTICO: LA CIUDAD DE TERUEL
}

\author{
José Luis Andrés Sarasa \\ Universidad de Murcia
}

\section{RESUMEN}

Las ciudades históricas, definidas por la interdependencia entre patrimonio cultural inmaterial y patrimonio cultural y natural, disponen de una ventaja cualitativa para posicionarse en la nueva función de la internacionalización.

El objetivo de este trabajo se centra en presentar y analizar el proceso llevado a cabo por la ciudad histórica de Teruel para ocupar un sitio en la nueva jerarquía urbana. Utiliza el mito de los Amantes como capital/imagen para realizar el proceso de su internacionalización. Un proceso que se concreta en tres estrategias, equivalente a otras tantas etapas que van de lo local a lo internacional, en las que participan un amplio conjunto de actores: el Centro de Iniciativas Turísticas con la entrega de la Medalla de los Amantes, la Fundación Bodas de Isabel en la recreación del mito y el Ayuntamiento busca la definitiva internacionalización con el Proyecto Europa Enamorada.

Palabras clave: patrimonio cultural inmaterial; mito; Amantes de Teruel; estrategias de desarrollo; destino turístico; actores locales.

\section{Myth and strategies for a romantic destination: the city of Teruel (Spain)}

\section{ABSTRACT}

The historic cities, defined by the interdependence between tangible and intangible cultural heritage and natural heritage, have a qualitative advantage to position themselves in the new function of internationalization.

The aim of this paper is to present and analyze the process conducted by the historic town of Teruel to occupy a place in the new urban hierarchy. The city uses the myth of the Lovers as the capital/image to make the process of internationalization. A process as embodied in

Recibido: 10 de septiembre de 2014

Devuelto para su revisión: 19 de febrero de 2015

Aceptado: 26 de marzo de 2015

Departamento de Geografía. Universidad de Murcia. Campus de La Merced. 30001 MURCIA (España). E-mail: jlandres@um.es 
three strategies, with different stages of development, from the local to the international, involving a wide range of actors: the Tourist Initiatives Center with the presentation of the Medal of the Lovers, the Foundation «Bodas de Isabel» in creating the myth, and the City Council, which seeks to internationalization with the project: Europe In Love.

Key words: intangible cultural heritage; myth; Lovers of Teruel; development strategies; tourist destination; local actors.

El proceso de globalización que impregna la vida económica, social, cultural y política fuerza a las ciudades a posicionarse para desempeñar una nueva función: la internacionalización. Una internacionalización que ha de propiciar una ciudad agradable, consumible, previsible y deseada, si quiere tener un sitio en la jerarquía urbana emergente.

Una pretensión que requiere un doble esfuerzo, en primer lugar, tener un mínimo de ambición internacional porque, como señala (Amendola, 2000) «hoy la ciudad nueva contemporánea vive de las transacciones y de los intercambios simbólicos, más que de la producción de bienes. Esta se orienta hacia el exterior y a las interconexiones y tiene su capital más valioso en la imagen y en la atracción». En segundo lugar, esta ambición implica a un amplio conjunto de actores (responsables políticos, empresarios, personalidades científicas, económicas y culturales, universidades, asociaciones, etc.), estrategias $\mathrm{y}$ recursos patrimoniales y humanos.

En estas circunstancias, las ciudades históricas definidas por la interdependencia que existe entre patrimonio cultural inmaterial y patrimonio material cultural y natural, disponen de una ventaja cualitativa que es preciso aprovechar hasta convertirla en instrumento clave para desempeñar la nueva función de la internacionalización. Una ventaja cualitativa que ha de venir determinada desde el saber hacer particular ante el complejo encuentro que hoy se produce, por una parte, entre modernidad y bienestar, y, por otra, entre innovación y tradición. Pilares básicos para fijar una emergente funcionalidad, que en la mayoría de los casos se define por la exclusividad a convertirse en ciudades turísticas. Una funcionalidad que debe potenciar la capacidad de desarrollo, tanto de la propia ciudad como de su ámbito de dominación.

Apostar por el patrimonio cultural inmaterial como instrumento de desarrollo exige admitir que el capital/imagen de la ciudad debe ser entendido como el texto que permita comprender el contexto en el que se configura la realidad social que lo ha producido, un texto que llevará a comprender el pasado, la personalidad de la ciudad, pero fundamentalmente el saber hacer de ayer y hoy.

El capital/imagen de la ciudad histórica de Teruel está constituido por la interdependencia apuntada más arriba, pero impregnada por el «mito» permanente, profundo y completamente enraizado en sí misma que son los Amantes. Un mito que se refiere a acontecimientos pasados, pero su valor intrínseco radica en que esos acontecimientos, que se supone ocurridos en un momento del tiempo, forman también una estructura permanente, que hace referencia simultáneamente al pasado, al presente y al futuro. Interesa matizar que entendemos por «mito» de los Amantes todo un conjunto de representaciones mentales nacidas de mensajes surgidos de una tradición del siglo XIII, convertido en historia a partir de 1619. 
La ciudad de Teruel está en el proceso de realizar el doble esfuerzo para su internacionalización, recrea el contexto que envuelve a la figura de los Amantes, hasta convertirla en el capital más valioso de su imagen, y cuenta con un conjunto de actores comprometidos con la difusión del «mito», entre otras iniciativas, cabe destacar las llevadas a cabo por el CITT, la Fundación Amantes, el Ayuntamiento y la Diputación.

El objetivo de este trabajo se centra en poner en valor el capital/imagen generado en torno al «mito» de los Amantes. La esencia del mito, su recreación y la apuesta por su valor como capital/imagen de la ciudad de Teruel encajan perfectamente en la definición de patrimonio cultural inmaterial que recoge el Artículo 2 de la Convención para la Salvaguardia del Patrimonio Cultural Inmaterial: «Se entiende por «patrimonio cultural inmaterial los usos, representaciones, conocimientos y técnicas, junto con los instrumentos, objetos, artefactos y espacios culturales que le son propios, que las comunidades, los grupos y en algunos casos los individuos reconozcan como parte integrante de su patrimonio cultural inmaterial, que se transmite de generación en generación, es recreado constantemente por las comunidades y grupos en función de su entorno, su interacción con la naturaleza y su historia, infundiéndoles un sentimiento de identidad y continuidad contribuyendo así a promover el respeto de la diversidad cultural y la creatividad humana».

En este sentido, en primer lugar se analiza el mito desde sus orígenes hasta destacar sus características fundamentales para convertirse en prototipo del amor romántico. Una vez puesto en valor el mito de los Amantes, se presentan las estrategias que la ciudad histórica de Teruel ha puesto en práctica para convertirse en agradable, deseada y consumible: la iniciativa local recogida en la Fundación Bodas de Isabel recrea el mito, el Centro de Iniciativas Turísticas promociona la ciudad romántica con la entrega de la Medalla de los Amantes, por último, la decisiva apuesta de los responsables municipales por la internacionalización de la ciudad lanza el Proyecto Europa Enamorada. En conjunto son una clara manifestación popular del patrimonio cultural inmaterial para la revitalización de la ciudad, convertida en destino turístico como ciudad romántica que se transmite de generación en generación.

La interrelación entre el mito y el destino turístico se produce con la reforma del mausoleo de los Amantes, cuyas instalaciones fueron inauguradas el 27 de septiembre de 2005. La financiación de las obras implicó a un amplio conjunto de actores locales: Ibercaja, Ayuntamiento de la ciudad, Diputación Provincial, Gobierno de Aragón y la Fundación Amantes (Institución sin ánimo de lucro, nace en 1998 para mantener y difundir la tradición de los Amantes, está sostenida por un Patronato promovido por el Obispo de Teruel/Albarracín, Ayuntamiento de Teruel, Gobierno de Aragón, Diputación Provincial e Ibercaja). Desde el año 2005 el número de visitantes ha superado ampliamente el millón, de los cuales la práctica totalidad lo hace atraídos por el mito de los Amantes. El 95\% de estos visitantes son españoles, el resto procede de 53 países distribuidos por los cinco continentes. Por provincias españolas ocupa el primer lugar Madrid, seguida de Valencia, Barcelona y Zaragoza. Por países destacan los franceses, casi con un tercio del total, seguidos de Italia, Alemania y Holanda. Semana Santa y el mes de agosto son las fechas con mayor afluencia de visitantes, por lo que se detecta una cierta estacionalidad. Jubilados, parejas y escolares es el perfil más destacado. 
Esta esperanzadora percepción en la generación del producto turístico exige una seria respuesta por parte de la ciudad, el éxito inicial puede propiciar una visión errónea del potencial turístico que lleve a sobredimensionar alguna de las estrategias con efectos negativos para la ciudad. Una vez tomada la decisión de crear el producto turístico, es preciso tener muy presente la regla de oro de toda planificación turística: un entorno de calidad constituye el elemento básico para transformar un espacio en destino turístico. Un entorno de calidad constituye la primera razón de ser de todo destino turístico que se precie. Una estrategia desbordada puede ser aniquilada por el propio turismo.

\section{EL MITO}

No se trata de interpretar el mito de los Amantes de una manera verosímil, tan sólo se pretende presentar el romanticismo que encierra, a la vez que superar el calificativo de leyenda que generalmente se le atribuye. Hay una clara diferencia entre los conceptos de leyenda y mito, que es preciso matizar para revalorizar el capital/imagen de la ciudad de Teruel. La leyenda hace referencia a un relato maravilloso que puede tener su origen en cierto acontecimiento histórico, pero siempre adornada con atributos fantásticos hasta crear versiones muy diferentes. En cambio el mito describe un acontecimiento que guarda estrecha relación con aspectos sociales o religiosos que forman parte de la tradición. Por esta razón los mitos tienden a influir en las costumbres de la sociedad que los genera.

Admitimos como mito de los Amantes de Teruel todo un conjunto de representaciones mentales nacidas de mensajes surgidos de una tradición del siglo XIII. La palabra «mito» proviene de griego «mythos», que el diccionario de la RAE interpreta como relato o noticia que desfigura lo que realmente es una cosa y le da apariencia de ser más valiosa o más atractiva. El diccionario de María Moliner lo define como representación deformada o idealizada de alguien o algo que se forja en la conciencia colectiva. «Ser más atractiva» $\mathrm{y}$ «se forja en la conciencia colectiva» son las bases de las estrategias que pone en marcha la ciudad. Las dos interpretaciones coinciden en la función principal que en este trabajo se pretende dar al mito, revelar hechos humanos con una gran carga significativa, poner de manifiesto que la narración mítica de los Amantes de Teruel revela las estructuras de lo real, esconde la imagen del propio mundo y descubre realidades sociales y culturales profundas.

El mito de los Amantes de Teruel constituye el prototipo del amor romántico de acuerdo con la teoría triangular del amor expuesta por Robert J. Sternberg (1989), que define el amor como una relación interpersonal con tres componentes características: intimidad -el componente del vínculo, conexión, de compartir los sentimientos del otro; pasión -el deseo de unión con el otro, expresión que vehicula algunas necesidades personales como el autoestima, satisfacción sexual, etc.-; compromiso -la decisión firme de permanencia junto a esa persona, de continuar con la relación de forma indefinida o permanente-. En el amor de los Amantes de Teruel están presentes la pasión y el vínculo íntimo, el desenlace les priva de mantener el compromiso de continuidad, por esta razón estamos ante un amor romántico. Sin embargo, el triunfo de la muerte les otorga la decisión final de permanecer juntos convirtiéndose en amor completo. En la aproximación al amor completo se basa la estrategia para calificar a la ciudad de romántica. 
Los fundamentos del mito de los Amantes de Teruel en este trabajo se abordan según las investigaciones llevadas a cabo por D. Isidoro de Antillón, publicadas en el $N^{\circ} 33 \mathrm{del}$ Memorial Literario -Nov., día 30=Trimestre $4^{\circ}$ del año 1806-NOTICIAS HISTÓRICAS sobre los Amantes de Teruel. Antillón inicia su relato dándole categoría de historia y admitiendo que es suficientemente conocida: «La historia trágica de los amantes de Teruel anda en boca de todos: se cuenta y se repite en todas las provincias de España».

Antillón presenta su trabajo afirmando que ofrece «Un corto discurso en donde el incidente de Marcilla y Segura quedará ilustrado con toda copia de noticias que ha podido recoger mi diligencia. Consta de siete artículos: el primero contiene la historia MS de los amantes que hallé este verano en el archivo de San Pedro de Teruel; el segundo trata de las diversas traslaciones de los cadáveres de Marcilla y Segura; el tercero del poema de Juan Yagüe; el cuarto de los testimonios de los historiadores; el quinto de la comedia de Montalván; el sexto de la relación estampada de una memoria genealógica de la casa de Garcés; el séptimo manifiesta el juicio que puede formarse acerca del origen y propagación de esta historia extraordinaria».

La esencia del mito, sus características y aspectos que lo definen se descubren en el primero de sus discursos. «Historia de los amantes de Teruel que conservaba a principios del S. XVII en el Archivo de esta Ciudad, en un papel de letra muy antigua, copió el Secretario Juan Yagüe según él mismo testifica como NOTARIO PUBLICO, esta copia existe ahora en la Iglesia parroquial de San Pedro de Teruel y es a la letra como sigue:

\section{«Historia de los amores de Diego Juan Martinez de Marcilla e Isabel de Segura. Año 1217; fue Juez de Teruel Domingo Celada:»}

Una advertencia previa, el mito de los Amantes de Teruel no puede entenderse si se lo separa de la vida de los hombres en su momento, no constituye una invención dramática sin relación con la organización social y política, con la ley o la costumbre, en realidad viene a justificarlas, como se pone de relieve en el párrafo siguiente: «Decimos de males y guerras, bueno es digamos de amores.... En Teruel está el de un joven llamado Diego Juan Martinez de Marcilla de unos 22 años enamorose de Isabel de Segura, hija de Pedro Segura, el padre no tenía otra, era muy rico; los jóvenes se amaban muy mucho en tanto que vivían afanados; y dijo el joven como deseaba tomarla por mujer y ella repuso ciertamente el deseo de ella era el mismo pero que supiera que nunca lo haría sin que su padre y madre se lo mandasen; ahora él la quiso más, quiso decírselo a su padre: su respuesta fue ciertamente él era muy bien pagado del joven y que vería bien; pero el no tenía bienes; y que su padre tenía otros hijos quien más lo podía heredar».

Inmediatamente relata el nacimiento de la esencia del valor del mito, tanto desde el punto de vista individual como de mensaje a la sociedad para derribar barreras que el corazón no entiende ni admite. Unas barreras que se concretan en: la marginación social por el dinero por encima del valor de la persona; el escaso protagonismo de la mujer en la sociedad medieval, ocupa un segundo plano en una actitud pasiva ante la concertación del matrimonio; la absoluta sumisión de la mujer al varón. «El joven dijo a la doncella que puesto que su padre no lo despreciaba, sino por los dineros; que si ella quería esperar cinco años que el se iría a trabajar y morir en las guerras alegre ya por mar, ya por tierra 
hasta tener dineros, al fin ella de nuevo se lo concedió y se ausentó en espacio de cinco años». Ambos toman sus propias decisiones, se desprende una negación de las premisas sociales ante el matrimonio. Ahí radica el valor romántico del mito.

El mito de los Amantes de Teruel reúne las características que definen al mito:

$1^{a}$ Aborda una pregunta existencial: el sacrificio por el amor. Isabel, durante el tiempo pactado, revela un gran respeto por el ser amado:«fue muy acosada del padre para que tomase marido, la respuesta de ella fue que había votado virginidad hasta que fuese de veinte años diciendo que las mujeres no debía casar sin que pudiesen regir su casa».

La verdadera expresión de la pregunta existencial tiene lugar en el aposento de los novios, Isabel antepone el sentimiento de fidelidad a la sumisión de la mujer en el matrimonio, no rompe con la decisión paterna de casarla pero impone su libertad, consciente de la presencia del compromiso por el amor completo, resiste al marido el derecho que le otorga el matrimonio, hasta cumplir esa noche el voto prometido al cielo.

Las palabras de Diego, tras la osadía de penetrar en el aposento, ensalzan el sacrificio por el amor, coloca el honor por encima de todo deseo. En un párrafo sublime se dirige a Isabel con gran respeto, pero ahondando en las razones sociales como causa de la situación que soportan: «Escúchame Segura, no te espantes que no es mi intento afrentar tu honor, aunque pudiera tomar justa venganza de mi injuria».

Diego descubre la entrega absoluta de sí mismo y de sus posesiones a la persona amada: «Solo vengo a que me digas, con qué motivo, habiéndote servido tantos años con un amor tan sencillo y verdadero, dejando por tu causa mis padres, mis deudos y mi patria, desterrándome a reinos extraños. Sin serlo por delito, exponiendo mi vida a las picas y a las lanzas, precediendo el haberme asegurado con firme juramento de no casarte sino conmigo, aguardando cinco años que aun apenas se han cumplido».

Existe una clara ofrenda emocional hacia el ser querido:» ¿Cómo, di, te has casado? ¿No me pudieras, di, aguardar más tiempo, pues apenas tienes cumplidos cuatro lustros?». Añade una fuerte valoración de la mujer a través de una fuerte denuncia social: «Desechome tu padre por ser pobre; por pobre me desechas tu también, por casarte con hombre rico: pobre confieso soy, y también que serás tú gran señora».

La escena concluye con una desgarradora llamada a la muerte para romper el compromiso y dar libertad a la amada, salvar el honor de Isabel y enterrar la pasión: «mas digote que imposible es que te quiera como yo te quiero, pues sabes que por ti padezco y muero».

\section{$2^{a}$ El mito de los Amantes de Teruel está constituido por contrarios irreconciliables: la vida frente a la muerte}

La gran contradicción de Diego aparece cuando reclama, en una expresión de deseo y necesidad no precisamente sexual, que «en premio de su fe y de sus servicios, del presente dolor y bien pasado, Marcilla le pidió a Segura un beso, con el cual estaría contento». En la respuesta de Isabel se evidencia el entendimiento mutuo con el amado: «confiésote, Marcilla, que en el tiempo que te amaba señora era de mí y de mis acciones; padecí en igual proporción tus penas y tus tormentos, y te confieso que el amor que me ligaba pudiera solo cortarle el cuchillo de la muerte». 
La lucha entre la vida y la muerte, anunciada por Diego en el apartado anterior, se reaviva con fuerza en un intenso deseo de unión carnal al volver a importunarla arrancando suspiros en vez de lágrimas «¿no consideras, di, dice Marcilla, que si no fuera yo tan cortesano tomara lo que te pido a fuerza, matando a tu esposo y mi enemigo?» Aparece ahora, de forma explícita, la situación que marca el final del compromiso naciendo de la muerte el amor romántico: «Y negándolo ella, dio un suspiro, diciendo: bésame, que sin remedio me muero; pero estando ella siempre firme en negarlo le dijo: a Dios Segura, y no pudo ya pronunciar la a. Quedó Segura sin habla y sin aliento y volviendo en sí dice: esposo de fe y de lealtad, crisol y centro ¿quién te ha quitado la vida tan repentinamente?».

La presencia irreconciliable de la vida ante la muerte trasciende de los protagonistas a la sociedad, son ejemplos claros las palabras del padre de Diego y los lamentos de la gente en el entierro. «Llegó su padre y sin poderlo estorbar se arrojó sobre el difunto bañándole con lágrimas el rostro y le dice:¡miserable de mi! ¿Después de haber sufrido tanta ausencia, y con ella a cada paso mil disgustos, me dan por consuelo tu muerte? Al punto me muero yo».

La sublimación del irreconciliable entre la vida y la muerte, pero también del amor romántico alimentado de la intimidad, lo proporciona Isabel cuando oye el lamentoso canto del entierro y que ella había sido la causa «por negar un ósculo a quien hubiera dado por ella dos mil vidas: fulmina contra sí un proceso, haciéndose reo, fiscal y juez y pronuncia la sentencia contra sí diciendo: que merece muerte quien mató al que debe la vida, acepta la sentencia y no la apela; afuera, dice, fama, que más quiero tenerla de liviana que de ingrata: no viviré yo más, porque a tu ejemplo quiero morir».

La muerte aparece como una clara expresión de deseo pero también de necesidad para el triunfo del amor romántico: «La procesión con el cuerpo llegaron a la Parroquial de San Pedro, Segura muy cubierta se llegó a donde estaba el féretro, y dice con ardentísimos suspiros ¿es posible que estando tú muerto tenga yo vida?».

Estos contrarios irreconciliables encierran la lucha entre los valores que honran y los que deshonran, ambos superados por la sublimación del amor que embriaga los dos pilares que sustentan a la sociedad: el honor y la honra. El desenlace pone de relieve como los protagonistas no pierden ninguno de esos valores y los refuerzan de cara a la sociedad con la fuerza del amor, es el mensaje que lanza el mito. Isabel mantiene la castidad femenina, su pérdida suponía la deshonra, pero cumple con la promesa al amado sin caer en la infidelidad con el esposo. El incumplimiento de la promesa y de la fidelidad suponía deshonra. La mujer aparece reforzada en su papel en la sociedad con una personalidad capaz de mayores protagonismos. Todos estos aspectos aparecen sintetizados en la Medalla de los Amantes, expresión de la condición que otorga a Teruel el calificativo de ciudad romántica. El escultor Juan de Ávalos pone las dos manos de los amantes aparentemente juntas pero sin tocarse, el honor por encima de la vida misma, por ello son merecedores de perdón.

$3^{a}$. Proporciona la reconciliación. «Quedaron como absortos sin sentido, sin poder resolver en este lance; más un viejo pariente de Marcilla, de mucha autoridad al que tenían sus razones por oráculo en voz clara dijo : supuesto que es verdad cierta que Marcilla y Segura desde niños se tuvieron un entrañable amor, y que en su ausencia larga han pasado 
los dos una pena y un tormento, y que ambos juntos han padecido un género de muerte será razón que se entierren los dos juntos en un sepulcro. El cual parecer fue aprobado de los dos padres de Marcilla y Segura, del Justicia y Regimiento, Azagra consintió y así se hizo».

$4^{a}$. El mito como producto social carece de autor, es anónimo. Pertenece al grupo social que lo relata, no se sujeta a ninguna transcripción y su esencia es la transformación. Las diversas escenificaciones, creyendo repetirlo, lo transforman.

En este sentido Antillón señala: «Si supongo que el origen de la celebridad de la historia o novela de los amantes se debe al hallazgo de sus cadáveres en 1.555. El nuevo reconocimiento en 1.619, aunque redactado en forma de escritura con notarios y testigos no existe original y ni aun en copia auténtica, en el archivo de la Iglesia de San Pedro de donde lo saqué este verano. Allí no hay más que una copia simple de letra de ayer, llena de erratas y transposiciones groseras; y en ella ni siquiera se expresa de donde se copió, o en que paraje se halla la escritura original. En Teruel me aseguraron que se halla en el archivo de una de las casas principales de Calatayud, acaso en la de Garcés, pero ignoro con qué fundamento sabía esta especie el que me lo dijo».

Antillón profundiza en el análisis del documento, además se siente comprometido con las cosas de su tierra, en la presentación de los artículos presume de ser de la tierra de los amantes y por esa razón se ocupa de un tema de tanta trascendencia social. Señala que «La relación de los amantes que he puesto en el $n^{\circ} 1$, aunque suena sacada de un papel muy antiguo de la casa del Ayuntamiento, es manifiestamente ficción de mano moderna, su misma lectura la indica, pues aunque las primeras cláusulas afecta el autor un estilo y locución anticuada después muda de giro y de voces notablemente, y es menester estar poco versado en nuestros historiadores para no conocer el lenguaje, las especies, y el continuo uso de retruécanos y equivoquillos manifiestan su nacimiento en el siglo XVII y por otra parte si antes de esta época hubiese existido en el archivo del Ayuntamiento ¿Cómo podría no tener noticia del él Yagüe, secretario del mismo, y exactísimo reconocedor de sus papeles según lo hace ver en sus obras sin embargo, al poner las bases del poema de los amante, a falta de documentos que narrasen su aventura, las estableció meramente sobre la tradición».

\section{LAS ESTRATEGIAS}

En este apartado se pretende dar a conocer como la iniciativa local está en la base de la nueva complejidad social, en ella participan responsables políticos, económicos, culturales y asociaciones. Una iniciativa que pone en marcha estrategias que revelan como la ciudad está abocada a la innovación, si en verdad quiere alcanzar la internacionalización que la posicione en la jerarquía urbana emergente.

Es preciso matizar que con el término innovación se hace referencia a toda capacidad para introducir una variación en la forma tradicional de afrontar el devenir de la ciudad. Introducir novedades significa cambiar, reformar y renovar. Aprehender una actitud distinta a la que se ha tenido durante años, forjar nuevas ideas, pero sobre todo, dotar de actividad, fuerza y validez a la puesta en valor del capital/imagen de la ciudad para afrontar los retos con una conducta nueva. 
Es preciso reafirmar que todo proceso de internacionalización de la ciudad está basado sobre las especificidades históricas y culturales de la propia ciudad. Que este proceso debe sustentarse en experiencias locales sólidas en torno a cuatro pilares básicos: cultura local, entendida como el saber hacer de las gentes en su vida cotidiana; asociacionismo, admitido como nuevo espíritu movilizador en busca de un objetivo común; democracia local, definida como elemento coordinador y organizador de todas las acciones; nuevas tecnologías, asumidas como instrumento de cambio, como innovación, como proceso de creación y nunca como un fin en sí mismas. Las tres estrategias puestas en práctica por la ciudad de Teruel -Bodas de Isabel, Medalla de los Amantes y Europa Enamorada- se sustentan plenamente en estos cuatro pilares.

\subsection{La ciudad romántica}

La representación colectiva crea la imagen que convierte a Teruel en una ciudad romántica por excelencia, no tanto por los rincones de la trama medieval de sus calles, donde surgen terrazas con sorprendentes vistas al apasionado mudéjar de sus torres salpicadas de leyendas de amor. Teruel se convierte en ciudad romántica por la historia de sus Amantes, imagen de síntesis de la ciudad, capaz de aglutinar los encantos de la ciudad con su historia. Para el turista, el visitante, la imagen de la ciudad romántica le permite percibir la esencia de la ciudad, descubrir sus nodos y puntos de referencia. Afirmar que Teruel es una ciudad romántica equivale a poner a disposición de los visitantes los instrumentos indispensables para desearla, soñarla y consumirla.

La relación de la ciudad con el mito en las estrategias para convertirse en destino turístico se sustenta en la corriente que a finales del siglo XIX vincula matrimonio con amor romántico, la unión estable de la pareja constituye la mayor expresión de amor romántico, se supera la idea del amor concertado, como le ocurrió a Isabel de Segura, y se impone el matrimonio por amor.

En un esfuerzo por valorizar el significado social de los Amantes, como imagen de la ciudad, se pone en práctica la iniciativa de honrar la convivencia de la pareja, la pervivencia del compromiso por encima de cualquier otra consideración, el mérito del matrimonio por amor. Una clara conexión con el tiempo de los Amantes donde primaba la idea de fortalecer y elogiar la institución del matrimonio. La estrategia se centra en agasajar a los matrimonios cuando cumplen sus Bodas de Plata, Oro y Platino, mediante la entrega solemne de la Medalla de los Amantes en cada una de las categorías. La estrategia pone de manifiesto la idea de que el amor romántico es la esencia, el pilar en el que se sustentan las relaciones matrimoniales. Formar una pareja, mantener el compromiso durante tantos años sólo es posible estando enamorados, con un amor romántico aglutinador de todas las pasiones, pero como resultado de una elección personal. Comportamiento que entronca con la doctrina de la Iglesia que no reconoce otra forma de relación que no sea la de pasar por el sacramento del matrimonio.

La estrategia Medalla de los Amantes, que convierte a la ciudad de Teruel en destino romántico por excelencia, nace en 1972 en un certamen organizado por el Centro de Iniciativas Turísticas de Teruel el fin de semana más próximo a San Valentín. El certamen «Medalla de los Amantes» homenajea a matrimonios que llevan 75 (Medalla de Platino), 50 (Medalla de Oro) y 25 (Medalla de Plata) años casados. Su concesión está regulada 
por un reglamento de honores y la correspondiente convocatoria. Una convocatoria que atrae a cientos de matrimonios de todo el país, con la consiguiente promoción del mito de los Amantes y de la propia ciudad. Con carácter extraordinario se conceden medallas a personas de relevancia social en un intento de difundir la promoción. La Medalla es obra de Juan de Avalos, autor del Mausoleo bajo el que reposan los restos de los Amantes.

El Centro de Iniciativas Turística de Teruel es una asociación privada constituida al amparo de la legislación española con la finalidad de colaborar con las administraciones públicas en la promoción de los recursos turísticos de la ciudad. Fue fundado en el año 1970, durante la primera década de su existencia contó con el patrocinio del Ministerio de Información y Turismo. En la Junta Directiva se integran todos los sectores y colectivos que tienen relación con la promoción del turismo. Para el desarrollo de sus numerosos actos cuenta con el patrocinio del Ayuntamiento de la ciudad, la Diputación y otras entidades públicas y financieras.

La entrega de la Medalla de los Amantes cuenta con un interesante programa de actos que, durante el fin de semana, se hacen partícipes de la universalidad de la historia de los Amantes recorriendo la ciudad y sus puntos de referencia más significativos: Iglesia de San Pedro, íntimamente ligada a los Amantes, Catedral, Ayuntamiento, torres Mudéjares y su enigmática trama urbana medieval, impregnando a estos matrimonios de un sentimiento romántico, que, sin duda, los convierte en los mejores embajadores de una ciudad enamorada. El sentimiento de los cientos de matrimonios que han participado en este certamen es unánime, hay que volver a Teruel, es preciso visitar Teruel.

El objetivo del Centro de Iniciativas Turísticas se consigue con creces, la promoción de la ciudad romántica se produce por su capacidad de seducción que la convierte, de hecho, en una ciudad turística. Todos los nodos y puntos de referencia incluidos en el recorrido del amor se convierten en lugares turísticos, no solo para los homenajeados, sino para sus referentes y para los propios habitantes de la ciudad que participan en los actos del homenaje. El fin de semana más próximo a San Valentín Teruel es una ciudad turística, todos son turistas, todos los ciudadanos se han convertido en turistas, pero con su promoción se consolida el destino turístico romántico por excelencia.

\subsection{Recreación del Mito}

La recreación del mito de los Amantes sintetiza el esfuerzo de aunar realidad y posibilidad, de interrelacionar el ser y la imagen, en un equilibrio complejo que se convierte en la atracción de la ciudad y en su encanto. Durante todo el año la ciudad establece con sus gentes una relación ambigua de fascinación, tanto a través de los diferentes momentos en los que el mito recorre las calles como por los preparativos y preocupaciones que la recreación exige. La ciudad de Teruel se convierte en «onírica» y toda ella es excitación, es mito. La ciudad queda permanentemente iconizada, se transforma en objeto de deseo y de consumo e impregna la vida cotidiana a lo largo de todo el año. La fascinación de la recreación del mito radica en la capacidad de sorprender siempre a propios y extraños.

En la recreación del mito la ciudad de Teruel se transfigura en un escenario de la vida cotidiana medieval, pero donde prima la ceremonia de la Iglesia, fiel reflejo de la descripción que hace Munford de la ciudad medieval, con una vida atareada y turbulenta, 
toda ella es escenario para el cortejo que impone la Iglesia: «La clave de la ciudad visible está en el espectáculo en movimiento o la procesión; y, sobre todo, en la gran procesión religiosa que da vueltas por las calles y las plazas antes de ir a desembocar, finalmente, en la iglesia o la catedral para la celebración de la gran ceremonia propiamente dicha. No se trata aquí de arquitectura estática. Repentinamente, las masas se dilatan o desvanecen, según se acerque uno a ellas o se aleje; una docena de pasos puede alterar la relación del primer plano y el fondo o el margen inferior y superior de la línea de visión. Los perfiles de los edificios, con sus gabletes empinados, sus líneas cortantes de techados, sus pináculos, sus torres, sus tracerías, ondean y fluyen, se rompen y solidifican, se levantan y caen, con menos vitalidad que las estructuras mismas. Como sucede en el caso de una buena escultura, los contornos son, a menudo, de una variedad inagotable».

El relato de sí misma y la retroalimentación del mito es fruto del esfuerzo de la Fundación Bodas de Isabel, que recrea el mito revalorizando nodos y puntos de referencia de la ciudad, convertidos en escenario de la imagen de la ciudad, donde se mezclan los encantos de la ciudad con su historia de amor para introducirse en el imaginario colectivo. La imagen de ciudad romántica se acrecienta y atrae tanto a los visitantes como a sus habitantes, todos ellos convertidos en protagonistas de la historia de amor.

La Fundación Bodas de Isabel surge de la propia sociedad turolense para recrear el mito de los Amantes con la participación de toda la ciudad. La primera celebración de las Bodas de Isabel de Segura fue el año 1977, pero tardó una década en consolidarse como una de las estrategias para convertir a Teruel en un destino romántico. Una decisiva intervención de los responsables municipales, junto con instituciones financieras y asociación de empresarios consiguen consolidar un acontecimiento cultural que emerge del seno de la sociedad turolense. El evento implica a grupos de la más diversa procedencia y estructura: teatro, músicos, personajes de la farándula, asociaciones culturales, colectivos complejos, comerciantes, centros docentes, talleres, etc., todos ellos se convierten en actores del drama, de la procesión o el desfile.

La lectura del Programa de actos de Las Bodas de Isabel de Segura 2015 desborda al visitante, la ciudad vestida al modo medieval se asemeja estéticamente a una tapicería de su época. En ella aparecen miles de turolenses organizados en torno a haymas y campamentos, a los que se suman cientos de actores que dan vida a la historia de los Amantes. Conciertos, exhibiciones, animación, mercado, teatro y muchas actividades convierten a Teruel en un destino turístico indiscutible como ciudad romántica. El elemento clave en la organización es la hayma, en total ciento cincuenta organizaciones que evocan la vida cotidiana del S. XIII, con sus actividades sorprenden tanto al propio ciudadano como a los visitantes, pero siempre fieles a cuanto significan las fiestas medievales, la música, la danza, los juegos, sin que falte el toro medieval, espectáculo que siempre apasiona en todas las fiestas que se precien, están presentes todo tipo de juegos y justas medievales, donde el caballero es protagonista de la fiesta.

Una evocación que se advierte en tres factores fundamentales: magnificación del honor y la honra medievales; actitud ante la vida y la muerte; el papel de la mujer y la familia. El honor es factor fundamental en la sociedad medieval y está relacionado con la propia existencia. En el siglo XIII, el código de Las Partidas afirma: «Honor es loor, reverencia e consideración que el hombre gana por su virtud e buenos hechos. Más aunque la honra se 
gana por actos propios, depende de actos ajenos, de la estimación y la fama que otorgan los demás. Así es que se pierde igualmente por actos ajenos, cuando cualquiera retira su consideración y respeto a otro, la deshonra es a par de muerte...». La actitud ante la muerte se recrea en torno a la mentalidad del hombre medieval que todo se concreta en la idea del juicio final. Al producirse la muerte de una persona se inician una serie de prácticas que se realizan en torno al difunto y hasta el momento de la inhumación. Los ritos estaban dominados por el duelo y las honras rendidas al difunto. Alrededor del cuerpo sin vida, la familia, los amigos, ahora silenciosos y aparentemente serenos, dejan de ser los principales intérpretes de la acción; en adelante los primeros papeles corresponderán a sacerdotes, frailes mendicantes, órdenes terceras o cofrades... Después del velatorio comenzaba el cortejo, ceremonia que ocupará un puesto considerable en el simbolismo de los funerales... Las manifestaciones de duelo que tienen lugar durante esta ceremonia dependen de la categoría social del difunto. (Molina Molina 1987). Respecto de la mujer y el matrimonio hay que insistir en que en la mentalidad clerical y aristocrática con respecto a la mujer, se traduce en la sujeción de ésta al varón. Sometimiento que no radicó sólo y exclusivamente en su condición femenina o en su estado civil, sino que dependió en la mayoría de los casos de las necesidades y exigencias de la sociedad. No es la naturaleza la que sitúa en un plano de inferioridad a la mujer; no es su debilidad física con respecto al varón, sino la propia sociedad, la mentalidad de la época... Entre los elementos de la alta sociedad y en la esfera de los comerciantes, artesanos y campesinos acomodados, los casamientos estaban, generalmente, precedidos de exigentes negociaciones económicas en las que la atracción física y los sentimientos amorosos de los interesados debían contar poco. (Molina Molina, 1987).

\subsection{EI Proyecto Europa Enamorada. (Europa In Love)}

La estrategia del Proyecto Europa Enamorada entronca plenamente con las dos ideas básicas que sustentan el desarrollo local endógeno en las ciudades históricas que buscan su internacionalización, por una parte, con la puesta en valor del patrimonio cultural y, por otra, con la movilización de las sinergias locales mediante la cooperación transnacional.

La puesta en valor del patrimonio cultural es un acierto indiscutible, porque «existe un alto grado de conexión entre la puesta en valor del patrimonio cultural y la mejora del nivel de calidad de vida en la ciudad. La mundialización de la economía y, todavía más, la globalización de los modos de producción y de intercambio, condicionan y estructuran inevitablemente la forma de cómo los bienes culturales son producidos, valorizadas e intercambiados. En junio de 1980 los expertos del comité de la UNESCO reunidos en Montreal, señalaban que la participación en la vida cultural y su corolario, el desarrollo de actividades culturales endógenas, están ligadas a la aceleración de la dinámica social y de los grupos tecnológicos. La perennidad del patrimonio inmaterial no puede hoy abstraerse de las dimensiones económicas y tecnológicas que fundamentan los procesos de globalización.....Se sabe que el reforzamiento del nivel cultural de una sociedad es una de las condiciones básicas para la creación de un entorno favorable al crecimiento de la productividad de sus diversos recursos» (Sid Ahmed, 2012).

Desde el punto de vista del desarrollo local los objetivos que se propone el Proyecto Europa Enamorada son equivalentes a los que puede plantearse una gran industria cultural 
dedicada a producir e intercambiar bienes culturales. Se trata de una iniciativa cultural en la que va a participar toda la sociedad en su doble vertiente, por una lado la institucional representada por el Ayuntamiento y, por otra, la técnica y social de la mano de la Fundación Bodas de Isabel, que, como se ha señalado, integra a todos los agentes sociales y coloca como actores fundamentales al conjunto de ciudadanos.

El proyecto pretende la valorización de las actividades culturales endógenas, para ello se propone crear una ruta de ciudades con historias de amor que promocionarán un turismo romántico. Una valorización cultural que surgirá de la profundización en la historiografía amantista, pero con la salvedad de que se superan los límites de lo local para convertirse en trasnacional, todo ello a través de recreaciones que marcarán los nodos de unas rutas turísticas promovidas por asociaciones e instituciones.

La fuerte implicación de las innovaciones tecnológicas facilitan al conjunto de actores compartir leyendas e historias de amor romántico y conformar un proyecto cultural con una constante común: la irreconciliación entre la vida y la muerte, que acaba superada por el amor. Una innovación tecnológica que, no sólo propiciará la divulgación de los avances de la historiografía logrados en el seno de equipos académicos e institucionales, debe ser elemento indispensable en la generación del destino turístico. La innovación tecnológica debe recurrir al SIG para confeccionar un mapa-calendario de las recreaciones turísticas integradas en el proyecto, apuntando las excelencias del patrimonio de la ruta, pero también una serie de elementos indispensables a la demanda turística, como alojamiento, gastronomía, actividades de ocio, valoración medioambiental de la ciudad, etc., que han de revertir en un fortalecimiento del nivel cultural.

Descubrir la segunda premisa básica en el Proyecto Europa Enamorada requiere insistir en que resulta prácticamente imposible alcanzar la internacionalización de la ciudad, como proyecto que integre las preocupaciones medioambientales, sociales, económicas y culturales, sin la movilización de las sinergias locales, movilización que se hace posible mediante el establecimiento de redes. Entendiendo por redes todo un sistema de relaciones y de flujos de información que facilitan la movilización de las sinergias para la integración en un proyecto común que ha de reportar beneficios a todos los integrantes de la red. La integración en el Proyecto se consigue mediante un modelo sustentado en la interdependencia y la complementariedad de todos los componentes de la red.

La ciudad de Teruel, entre las distintas modalidades de cooperación internacional, para lanzar su proyecto Europa Enamorada, opta por la búsqueda de redes para alcanzar el objetivo de posicionar a la ciudad en la nueva jerarquía urbana. La búsqueda de ciudades con intereses y valores culturales comunes, capaces de llevar a cabo iniciativas de desarrollo con la participación directa en el proyecto, es un proceso que conlleva varias etapas y que debe iniciarse con la puesta en marcha de foros donde cada ciudad plantea su propuesta a la vez que debate sobre el conjunto. En este sentido la ciudad de Teruel, para confeccionar la red de ciudades románticas ha mantenido los siguientes contactos:

La Ciudad de Verona, escenario elegido por Shakespeare para el drama romántico de Romeo y Julieta. Uno de los lugares más visitados por los tres millones de turistas es el famoso «Balcón de Julieta», donde sorprenden los numerosísimos mensajes de amor pegados de sus paredes de las más insospechadas maneras. 
Montecchino Maggiore, rival de Verona por la historia de Romeo y Julieta, pues afirman que surge aquí de la mano del Conde Luigi Da Porto, convaleciente de heridas de guerra contempla dos lomas, donde se levantan los castillos de los Capuleto y los Montesco, dos familias rivales, sus escritos inspiran a Shakespeare.

Sulmona, localidad italiana, próxima a Roma, cuna de Ovidio. Autor que influyó poderosamente en la literatura romántica de la Edad Media con su obra El arte de amar.

Coimbra, ciudad portuguesa, cuna del amor entre Inés de Castro y el príncipe heredero Pedro de Portugal. Una relación de amor que es rechazada por el rey Alfonso IV y que zanja con el asesinato de Inés, a la muerte del rey, Pedro recupera el cuerpo de la amada y la sienta en el trono para que reciba los honores de parte de la nobleza.

El Proyecto pretende incorporar más ciudades con el objetivo de solicitar fondos de la UE, si participan tres países se presenta al Programa Europa Creativa, pero si son más los países implicados puede hacerlo al programa Interreg. Por esta razón ha entrado en contacto con la ciudad medieval de Sigulda (Letonia), su historia de amor se sustenta en una tumba y un árbol; la ciudad de Krosno (Polonia), recrea la historia de amor entre dos medio hermanos; en la isla de Creta contacta con un centro de estudios de Heraclion con la leyenda del Minotauro. Todas ellas coinciden en hacer del amor un reclamo turístico.

\section{CONCLUSIONES}

La ciudad de Teruel está inmersa en el proceso de aprovechar su patrimonio cultural inmaterial y el patrimonio material cultural y natural para posicionarse en la emergente jerarquía urbana. Un proceso que gira en torno al mito de los Amantes, convertido en capital/ imagen de la ciudad a través de las estrategias surgidas de la iniciativa de un conjunto de actores, que pretenden convertir a la ciudad en un destino turístico calificado de romántico.

El mito de los Amantes, definido como prototipo del amor romántico, reúne las características y la esencia que definen al mito, es un verdadero mensaje a la sociedad y no puede entenderse aislado de la vida cotidiana de las gentes del momento. Todo el mito gira en torno a dos pilares básicos, el sacrificio por el amor y el irreconciliable entre la vida y la muerte. El sentimiento de de fidelidad, la entrega hacia el ser amado, la valoración sin límites de la persona amada, la continua llamada a la muerte, la presencia irreconciliable de la vida ante la muerte, son valores que trascienden de los protagonistas y conducen a la cristalización del amor romántico.

El amor romántico es objeto de la representación colectiva a través de unas estrategias que configuran las etapas del proceso de internacionalización de la ciudad. Representar, potenciar, defender que Teruel es una ciudad romántica por excelencia equivale a ofrecer a los visitantes la posibilidad de desearla, soñarla y consumirla. La primera estrategia, la Medalla de los Amantes, vincula el matrimonio al amor romántico porque la estabilidad de la pareja es entendida como la mayor expresión de amor romántico. La segunda estrategia, la recreación del mito, las Bodas de Isabel, se presenta como un esfuerzo por aunar realidad y posibilidad, interrelacionar el ser y la imagen, todo ello en un equilibrio complejo que transforma a la ciudad en un escenario de la vida cotidiana medieval, donde prima la ceremonia de la iglesia y se magnifican las diferencias sociales. El acontecimiento implica a grupos de la más diversa procedencia y estructura, habitantes de la ciudad y visitantes 
se convierten en actores del drama, representado en la trama urbana medieval. Por último, el Proyecto Europa Enamorada es el paso definitivo para la internacionalización de la ciudad, se propone la creación de una ruta de ciudades históricas de amor promocionando un turismo romántico. Para alcanzar este objetivo se apuesta por crear una red de ciudades con intereses y valores culturales comunes, se pretende sea lo más amplia posible para obtener fondos de la UE en el programa Interreg.

\section{BIBLIOGRAFÍA}

AMENDOLA, G. (2000): La ciudad postmoderna. Celeste Ediciones. Madrid.

ANDRÉS FERRER, P. (2002): «J.L. Borges: <La casa de Asterión>, recreación intelectual de un mito». Espéculo. Revista de Estudios Literarios, n ${ }^{\circ} 19$.

ANDRÉS SARASA, J.L. (1995): «La gente es consumidora de mitos...El mito turístico del Mar Menor», Papeles de Geografía, no 22, pp. 5-17.

ANDRÉS SARASA, J.L. (2007): «Funzione internacionales e costituzionales delle Città» . Ponencia en el VIII Seminario della Conférence permanente des Villes Historiques de la Méditerranée. Carbonia (Italia).

ANDRÉS SARASA, J.L. y ESPEJO MARÍN, C. (2006): «Interacción mito religioso/producto turístico en la imagen de la ciudad: Caravaca de la Cruz (Murcia)», Cuadernos de Turismo, $\mathrm{n}^{\circ} 18, \mathrm{pp} .7-61$.

DIZ ARDIZ, E., LOBRANO, G., ANDRÉS SARASA, J.L., SID AHAMED, A. (Dirs.) (2012) Le gouvernement des villes: Démocratie et efficacité. Compétence et coopération en Méditerranée: droit, Economie et urbanisme. ISPROM-VILLE DE ORIHUELA-PUBLISUD.

DUBY, G. (1990): El amor en la Edad media y otros ensayos. Ed. Alianza. Madrid.

ESTEBAN GALARZA, M.L. (2008): «El amor romántico dentro y fuera de occidente: determinismos, paradojas y visiones alternativas», en Feminismos en la Antropología: Nuevas apuestas críticas. $n^{\circ}$ 6. Ed. Ankulegi. Universidad del País Vasco.

ESTEBAN, M.L. y TOVARA, A. (2008): «El amor romántico y la subordinación social de las mujeres: revisiones y propuestas». Anuario de Psicología, no 39 (1), pp. 59-73.

FERRER, V.A., BOSCH, E. y NAVARRO, C. (2010): «Los mitos románticos en España», Boletín de Psicología, $\mathrm{n}^{\circ}$ 99, pp. 7-31.

LÉVI-STRAUSS (1974) «La estructura de los mitos». Antropología estructural. A.E.I. Ed. EUDEBA. Buenos Aires.

LÉVI-STRAUSS (1986): Mito y significado. Alianza Editorial. Buenos Aires.

LOBRANO, G., ANDRÉS SARASA, J.L. y SID AHMED, A. (Dirs.) (2007): Une stratégie de développement durable pour les villes historiques de la Méditerranée et leurs territoires. Conference permanente des Villes Historiques de la Méditerranée. ISPROMVILLE DE LORCA-PUBLISUD.

LOSADA, J.M. y LIPSCOMB, A. (1988): Mito e interdisciplinariedad. Los mitos antiguos, medievales y modernos en la literatura y en las artes contemporáneas. Levante Ediciones. Bari (Italia).

MOLINA MOLINA, A.L. (1987): La vida cotidiana en la Murcia bajomedieval. Academia Alfonso X El Sabio. Murcia. 
MUMFORD, 1. (1979): La ciudad en la Historia. Ediciones Infinito. Buenos Aires.

SANGRADOR, J.L. (1993): «Consideraciones psicosociales sobre el amor romántico», Psicothema, vol 5, Suplemento, pp. 181-196.

STERNBERG, R. (1989): El triángulo del amor. Paidos. Barcelona.

VALDÉS GUÍA, M. (2009): «La recreación del pasado en el imaginario griego: el mito de Teseo y su utilización como fuente histórica», Dialogues d'histoire ancienne, $\mathrm{n}^{\circ}$ 35/1, pp. 11-40.

VILCHES DE FRUTOS, M.F. (1983): «Introducción al estudio de la recreación de los mitos en el teatro de la postguerra española», Segismundo: Revista hispánica de teatro, $\mathrm{n}^{\mathrm{o}}$ 37-38, pp. 183-209.

YELA, C. (2002): El amor desde la psicología social. Ni tan libres ni tan racionales. Ed. Pirámide. Madrid.

YELA, C. (2003): «la otra cara del amor, paradojas y problemas», Encuentros en Psicología Social, 1 (2), pp. 263-267. 